\title{
Contribution of Arab researchers to ophthalmology: a bibliometric and comparative analysis
}

\author{
Waleed M Sweileh ${ }^{1 *}$, Samah W Al-Jabi ${ }^{2}$, Yousef I Shanti ${ }^{3}$, Ansam F Sawalha ${ }^{1}$ and Sa'ed H Zyoud ${ }^{2}$
}

\begin{abstract}
Through history, Arabs and Muslims have made valuable contribution to medicine and science. The main objective of this study was to assess the contribution of Arab researchers to ophthalmology using bibliometric indicators. Published articles in "Ophthalmology" authored by Arab researchers were screened and analyzed using ISI Web of Science database. Worldwide research productivity in ophthalmology was 216,921 documents while that from Arab countries; Israel, Turkey and Iran were 2083, 2932, 3027 and 859 documents respectively. Those from Arab countries were published in 85 peer-reviewed ophthalmology related journals with 280 (13.44\%) documents published in Journal Francais d Ophtalmologie. Among Arab countries, Kingdom of Saudi Arabia had the highest (828 (39.75\%)) research output followed by Egypt $(461$ (22.13\%)) and Tunisia 210 (10.08). Countries with highest collaboration with researchers in Arab world in ophthalmology research were USA; $(397 ; 19.06 \%)$ followed by England $(92 ; 4.42 \%)$ and Spain $(91 ; 4.37 \%)$. The most research productive organization in Arab countries was King Khalid Eye Specialist Hospital (396; 19.01\%). Ophthalmology articles authored or co-authored by an Arab researcher had a total citation $\mathrm{f} 21098$ with an average citation of 10.13 per document and an $h$-index of 51. In conclusion, the present data show promising increase but relatively low ophthalmology research productivity from Arab countries. Wide variation in research productivity do exists. Compared with other non-Arab countries in the Middle East, Arab countries showed lesser ophthalmology research activity than Israel and Turkey but higher than that in Iran.
\end{abstract}

Keywords: Bibliometric; Ophthalmology; Arab world; ISI Web of Science

\section{Background}

Ophthalmology is a branch of medicine that deals with health problems of the eye. Arab and Muslim scholar have made valuable contribution to modern medicine in general and ophthalmology in particular (Syed 2002; Huff 2003; Majeed 2005). For example Ibn al-Haytham (Alhazen), an Arab and Muslim scientist, wrote extensively on optics and the anatomy of the eye. Actually, Ibn al-Haytham is considered the one who made the first steps in the science of vision through his writings and explanations (Gorini 2003). Another Arab Muslim scientist is Ibn al-Nafis who lived in Damascus and wrote about medicine and eye diseases (Prioreschi 2006). In the past century, ophthalmology became an important medical, surgical, genetic and public health discipline. Furthermore, many medical institutions around

\footnotetext{
* Correspondence: waleedsweileh@yahoo.com

'Department of Pharmacology and Toxicology, College of Medicine and Health Sciences, An-Najah National University, Nablus, Palestine Full list of author information is available at the end of the article
}

the world became highly specialized in research, education and clinical practice of ophthalmology. Similarly, many new and potent ocular medications have been developed to overcome eye diseases including glaucoma, an important risk factor for blindness. Antibiotics have also made many eye infections easy to control and treat. Modern techniques and computerization have also helped detect and solve many visual problems. In the Arab world, medical education and clinical practice have witnessed a dramatic change especially in the past three decades. Many medical schools, hospitals, and specialized medical research centers have been established. However, it is believed that research in Arab countries in various medical fields is still lagging behind compared to non-Arab countries in the region (Al-Khader 2004; Benamer and Bakoush 2009; Bissar-Tadmouri and Tadmouri 2009; Farhat et al. 2013; Zyoud et al. 2014d). No data is available regarding the status and research output in ophthalmology from Arab countries. This specialty of medicine is of great importance to the Arab world because many risk factors for 
blindness, like diabetes mellitus, are prevalent in the Arab world. Actually, 6 out of the world's top ten countries for highest prevalence of diabetes are in the Middle East (Whiting et al. 2011). Actually, many Arab researchers are aware of this and have launched peer reviewed journals dedicated for Ophthalmology to encourage Arab researchers in this field (e.g. Saudi Journal of Ophthalmology). Research in ophthalmology reflects excellence and quality of medical education, clinical practice, public health standards and public awareness related to eye and vision problems. One method to assess research activity in any country or region is to do bibliometric analysis which refers to the implementation of statistical methods for evaluating research productivity (Wallin 2005). Therefore, the objective of this study was to analyze research output by investigators in Arab countries in the field of ophthalmology. Bibliometric analysis of research activity as well as citation analysis of influential authors and researchers in ophthalmology has been investigated from different parts of the world (Davis and Wilson 2001, 2003; Ohba 2005; Ragghianti et al. 2006; Fan and McGhee 2008). However, up to the author's best knowledge, none has been published from the Arab countries. It is believed that a bibliometric analysis in ophthalmology can lead to better preventive health policy and health services in the field of ophthalmology.

\section{Materials and methods}

The data used in this study were based on the ISI Web of Science (WoS). All Arab countries, except Palestine, were used as country keys followed by "ophthalmology" as WoS category in advanced search engine of ISI WoS. Palestine was excluded from search keys because the Web of Science database does not recognize Palestine as an independent state yet. The time frame for the result was 1900 - 2012. The types of documents included were original research articles and review articles while other types were excluded.

Bibliometric indicators presented in the results include $h$-index which represents the number of citations received for each of the documents in descending order (Baldock et al. 2009; Schreiber 2013). Other indicators considered were top-ten ranked journals and the journal impact factor (IF) which was evaluated using the Journal Citation Report (JCR; Web of Knowledge) 2012 science edition by Thomson Reuters (New York, NY, USA). The SCImago Journal Rank (SJR) indicator was also included (Available at: http://www.scimagojr.com/SCImagoJournalRank.pdf). Scientific research output in the field of CAM was measured based on a methodology developed and used in previous bibliometric studies (Sweileh et al. 2014a; Sweileh et al. 2014d; Zyoud et al. 2014a, b; Zyoud et al. 2014d, e; Zyoud et al. 2014c). The collected data were used to generate the following information: (a) total and trends of contributions in ophthalmology research during all previous years up to the set date of data analysis (December 31th, 2012); (b) Arab countries research productivity and collaboration patterns; (c) journals in which Arab world researchers published; and (d) the citations received by the publications.

\section{Results}

The total number of documents retrieved from ISI Web of Science using "Ophthalmology" subject category without specifying the name of any country was 216,921. This number represents the global research productivity (original research articles and reviews) in ophthalmology subject up to year 2012. When the same methodology was applied using the list of the 21 Arab countries, 2083 documents (2035 original articles and 48 review articles) in ophthalmology were retrieved. Therefore, research output in ophthalmology from Arab countries represents $0.96 \%$ of the global research productivity in ophthalmology. The annual number of documents published from Arab countries indicated that ophthalmology research output remained low until mid-1990s (Figure 1A and B). More than $50 \%$ of documents were published after the year 2005 . The language of most documents was English (1780; 85.45\%) followed by French (286; 13.73\%), and German
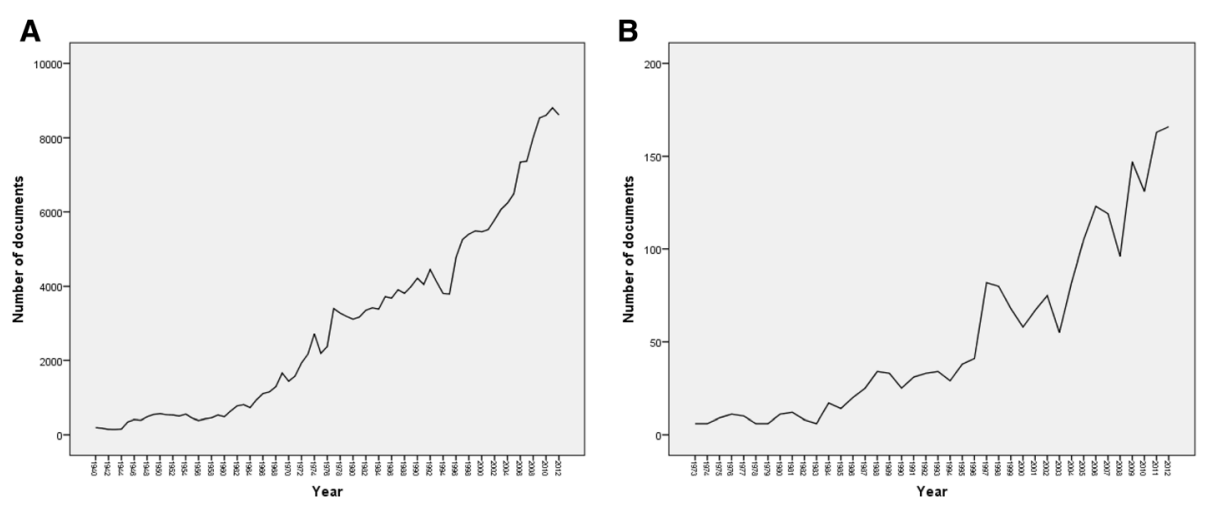

Figure 1 Annual growth of ophthalmology research. A. Worldwide. B. Arab world. 
(17; 0.82\%) languages. The first ophthalmology article from Arab countries was published in 1933 in Archives of Ophthalmology (currently named as JAMA ophthalmology) from Egypt with the following title "Trachoma in Egypt" (Olitsky and Tyler 1933).

The retrieved documents were published in 85 peerreviewed ophthalmology related journals. Two hundred and eighty documents (13.44\%) were published in Journal Francais d Ophtalmologie which started in 1978. Table 1 lists the top 10 journals in which documents in the field of ophthalmology were published from the Arab countries. Of the 2083 ophthalmology documents, there were 291 (13.97\%) documents in surgery, 128 (6.15\%) in pediatric and $60(2.88 \%)$ in biochemistry/ molecular biology research area.

When retrieved data were analyzed based on country contribution (Table 2), Kingdom of Saudi Arabia (KSA) had the highest $(828(39.75 \%))$ research output followed by Egypt (461 (22.13\%)) and Tunisia 210 (10.08). No data related to ophthalmology was found from Djibouti and Mauritania. Approximately $62 \%$ of ophthalmology research from Arab countries came from KSA and Egypt. Collaboration in ophthalmology research with non-Arab countries was evident. Countries whose researchers collaborated most with researchers in the Arab world include the United States of America (USA); (397; 19.06\%) followed by England (92; 4.42\%) and Spain (91;

Table 1 Top 10 journals in which ophthalmology documents from Arab countries were published

\begin{tabular}{|c|c|c|c|c|}
\hline \multirow[t]{2}{*}{ SCR } & \multirow[t]{2}{*}{ Journal name } & $\begin{array}{l}\text { Number of } \\
\text { documents }\end{array}$ & \multirow[t]{2}{*}{$\mathrm{IF}^{\mathrm{a}}$} & \multirow[t]{2}{*}{$S J R^{k}$} \\
\hline & & $N(100 \%)=2083$ & & \\
\hline $1^{\text {st }}$ & $\begin{array}{l}\text { Journal Francais } d \\
\text { Ophtalmologie }\end{array}$ & $280(13.44)$ & 0.438 & 0.23 \\
\hline $2^{\text {nd }}$ & $\begin{array}{l}\text { British Journal of } \\
\text { Ophthalmology }\end{array}$ & $149(7.15)$ & 2.725 & 1.7 \\
\hline $3^{r d}$ & Ophthalmology & $118(5.67)$ & 5.563 & 3.86 \\
\hline $4^{\text {th }}$ & $\begin{array}{l}\text { Journal of Cataract and } \\
\text { Refractive Surgery }\end{array}$ & $102(4.90)$ & 2.527 & 1.64 \\
\hline $5^{\text {th }}$ & $\begin{array}{l}\text { American Journal of } \\
\text { Ophthalmology }\end{array}$ & $100(4.80)$ & 3.631 & 2.96 \\
\hline $6^{\text {th }}$ & $\begin{array}{l}\text { Journal of Refractive } \\
\text { Surgery }\end{array}$ & $94(4.51)$ & 2.474 & 1.93 \\
\hline $7^{\text {th }}$ & $\begin{array}{l}\text { European Journal of } \\
\text { Ophthalmology }\end{array}$ & $75(3.60)$ & 0.912 & 0.67 \\
\hline $8^{\text {th }}$ & Journal of AAPOS & $70(3.36)$ & 0.731 & 0.59 \\
\hline $9^{\text {th }}$ & Eye & $69(3.31)$ & 1.818 & 1.18 \\
\hline $10^{\text {th }}$ & Molecular Vision & $60(2.88)$ & 1.987 & 0.88 \\
\hline
\end{tabular}

Abbreviations: $\mathrm{SCR}=$ Standard Competition Ranking; IF = impact factor; $\mathrm{SJR}=$ Scientific Journal Ranking

${ }^{\text {a }}$ The impact factor was reported according to Institute for Scientific

Information (ISI) journal citation reports (JCR) 2012.

${ }^{\mathrm{b}}$ The Scientific Journal Ranking was reported according

to "http://www.scimagojr.com/".
Table 2 Contribution of each Arab country in ophthalmology research output

\begin{tabular}{|c|c|}
\hline Country & $\begin{array}{l}\text { Number of documents } \\
N(\%)=2083(100 \%)^{*}\end{array}$ \\
\hline Saudi Arabia & $828(39.75)$ \\
\hline Egypt & $461(22.13)$ \\
\hline Tunisia & $210(10.08)$ \\
\hline Lebanon & $184(8.83)$ \\
\hline Morocco & $133(6.39)$ \\
\hline Oman & $98(4.71)$ \\
\hline Kuwait & $56(2.69)$ \\
\hline United Arab Emirates & $49(2.35)$ \\
\hline Jordan & $47(2.26)$ \\
\hline Algeria & $22(1.06)$ \\
\hline Syria & $16(0.77)$ \\
\hline Qatar & $15(0.72)$ \\
\hline Sudan & $11(0.53)$ \\
\hline Bahrain & $7(0.34)$ \\
\hline Libya & $7(0.34)$ \\
\hline Iraq & $6(0.29)$ \\
\hline Yemen & $5(0.24)$ \\
\hline Comoros & $2(0.1)$ \\
\hline Somalia & $2(0.1)$ \\
\hline Mauritania & 0 \\
\hline Djibouti & 0 \\
\hline
\end{tabular}

*Total exceeds $100 \%$ because of overlap in some documents among more than one Arab country.

4.37\%); (Table 3). When data regarding collaboration was analyzed for the top three Arab countries, we found that countries whose researchers collaborated most with researchers from KSA include the USA (205; 9.8\%), Belgium (36; 1.7\%), UK (27; 1.3\%); Canada (20; $1.0 \%)$, and Spain (12; 0.6\%). Egypt researchers collaborated most with researchers from the USA (89; 3.3\%), Spain (67; 3.2\%), England (35; 1.7\%), Switzerland (19; $0.9 \%$ ), and Germany (17; $0.8 \%)$. In addition, Tunisia researchers collaborated most with researchers from the USA (17; 0.8\%), France (16;0.8\%), India (4;0.2\%), Italy (4; $0.2 \%)$, and Japan $(4 ; 0.2 \%)$. Of interest, the top productive institution was King Khalid Eye Specialist Hospital in KSA $(47 ; 11.03 \%)$. Five of the top 10 productive institutions were based in KSA while 4 were based in Egypt (Table 4).

Table 5 shows the top 10 most active organizations in Arab countries in the field of Ophthalmology. The most research productive organization was King Khalid Eye Specialist Hospital $(396 ; 19.01 \%)$. Nine out of top 10 active organizations are located in KSA or Egypt. The American University in Beirut was the only organization based outside the gulf and Egypt and was among the top 
Table 3 Top 10 countries whose researchers have collaborated with Arab researchers in publication of the 2083 documents in ophthalmology

\begin{tabular}{lll}
\hline $\mathbf{S C R}^{\mathbf{a}}$ & Country & $\begin{array}{l}\text { Number of documents } \\
\mathbf{N}(\%)=\mathbf{2 0 8 3}(\mathbf{1 0 0 \% )}\end{array}$ \\
\hline $1^{\text {st }}$ & United States of America & $397(19.06)$ \\
$2^{\text {nd }}$ & England & $92(4.42)$ \\
$3^{\text {rd }}$ & Spain & $91(4.37)$ \\
$4^{\text {th }}$ & Germany & $52(2.5)$ \\
$5^{\text {th }}$ & Belgium & $50(2.4)$ \\
$6^{\text {th }}$ & France & $46(2.21)$ \\
$7^{\text {th }}$ & Canada & $45(2.16)$ \\
$8^{\text {th }}$ & India & $30(1.44)$ \\
$9^{\text {th }}$ & Switzerland & $27(1.30)$ \\
$10^{\text {th }}$ & Japan & $24(1.15)$ \\
\hline
\end{tabular}

Abbreviations: SCR = Standard Competition Ranking.

10 active organization. The total number of citations, at the time of data analysis (April 27th, 2014), was 21098 with an average citation of 10.13 per document. Of the 2083 documents considered for the h-index, 51 had been cited at least 51 times at the time of data analysis. Figure 2 shows the changes in the total number of citations in each year which reflects the changes in quality of publication in ophthalmology from Arab countries. Compared with other non-Arab countries in the Middle East, the research productivity from the Arab countries was lesser than that from Turkey (3027) and Israel (2932) and but higher than that from Iran (859). Table 5 shows a comparison between Arab countries and 3 non-Arab

Table 4 Top 10 active organizations in the field of ophthalmology in Arab countries

\begin{tabular}{|c|c|c|c|}
\hline$S C R^{a}$ & Organization & $\begin{array}{l}\text { Number of } \\
\text { documents } \\
\mathrm{N}=2083(100 \%)\end{array}$ & Country \\
\hline $1^{\text {st }}$ & King Khalid Eye Specialist Hospital & $430(20.64)$ & KSA \\
\hline $2^{\text {nd }}$ & King Saud University & $296(14.21)$ & KSA \\
\hline $3^{\text {rd }}$ & American University Beirut & $148(7.11)$ & Lebanon \\
\hline $4^{\text {th }}$ & Cairo University & $100(4.8)$ & Egypt \\
\hline $5^{\text {th }}$ & $\begin{array}{l}\text { King Faisal Specialist Hospital } \\
\text { Research Centre }\end{array}$ & $78(3.75)$ & KSA \\
\hline $6^{\text {th }}$ & $\begin{array}{l}\text { Research Institute of } \\
\text { Ophthalmology }\end{array}$ & $69(3.31)$ & Egypt \\
\hline $7^{\text {th }}$ & $\begin{array}{l}\text { King Abdulaziz University } \\
\text { Hospital }\end{array}$ & $64(3.07)$ & KSA \\
\hline $8^{\text {th }}$ & Ain Shams University & $50(2.4)$ & Egypt \\
\hline $9^{\text {th }}$ & University Alexandria & $47(2.26)$ & Egypt \\
\hline $10^{\text {th }}$ & The Eye Center & $42(2.02)$ & KSA \\
\hline
\end{tabular}

Abbreviations: SCR = Standard Competition Ranking; KSA = Kingdom of Saudi Arabia.
Table 5 Ophthalmology research output from Arab countries compared with that from Turkey, Israel and Iran

\begin{tabular}{lllll}
\hline Variable & Arab countries & Israel & Iran & Turkey \\
\hline Number of results found & 2083 & 2932 & 859 & 3027 \\
$\begin{array}{l}\text { Sum of the Times Cited } \\
\text { Sum of Times Cited without }\end{array}$ & 21098 & 39132 & 5282 & 24104 \\
self-citations & 19809 & 37066 & 4839 & 22136 \\
$\begin{array}{l}\text { Citing Articles } \\
\text { Citing Articles without }\end{array}$ & 16135 & 30376 & 4216 & 17521 \\
self-citations & 15460 & 29316 & 3961 & 16467 \\
Average Citations per Item & 10.13 & 13.35 & 6.15 & 7.96 \\
$h$-index & 51 & 70 & 31 & 46 \\
\hline
\end{tabular}

countries with regard to citation analysis for published ophthalmology documents.

\section{Discussion}

The goal of the current study was to analyze the quality and quantity of ophthalmology research from Arab countries. It is true that few review articles about ophthalmology practice have been published from certain Arab countries in the past 2 decades (Tabbara and Blodi 1987; Wagoner and al-Rajhi 2001), however, no bibliometric analysis about ophthalmology research activity in Arab countries have been published. The importance of our study can be attributed to the following points: (1) ophthalmic diseases, including infectious diseases, and visual problems are common in Arab countries (Olitsky and Tyler 1933; Inhorn Millar and Lane 1988; Mansour et al. 1997; Tabbara 2001; Kotb et al. 2006; Saadi et al. 2007); (2) the huge urbanization and modernization, particularly in some Arab countries like Gulf states, need to be paralleled with a general increase in medical and ophthalmology research; (3) risk factors like poverty, poor hygiene, diabetes mellitus, hypertension, genetic diseases, poor nutrition are present in most Arab countries and finally (4) the advancement in the medical and surgical aspects of ophthalmology requires genuine attention from specialists and practitioners in Arab world to match their counterparts in non-Arab countries in Middle Eastern region.

Based on the results obtained in this study, research productivity from Arab countries in ophthalmology is relatively lagging behind. The rich heritage of Arabs in the field of vision and ophthalmology should give Arab nations a huge momentum in this field. With a total population of approximately 400 million, the number of documents in ophthalmology published from Arab countries requires a thoughtful analysis. Several potential reasons could be cited here. For example, the lack of specialists in this field might be a major contributor for the relatively low research productivity. Up until recently, most medical students who wanted to specialize in 


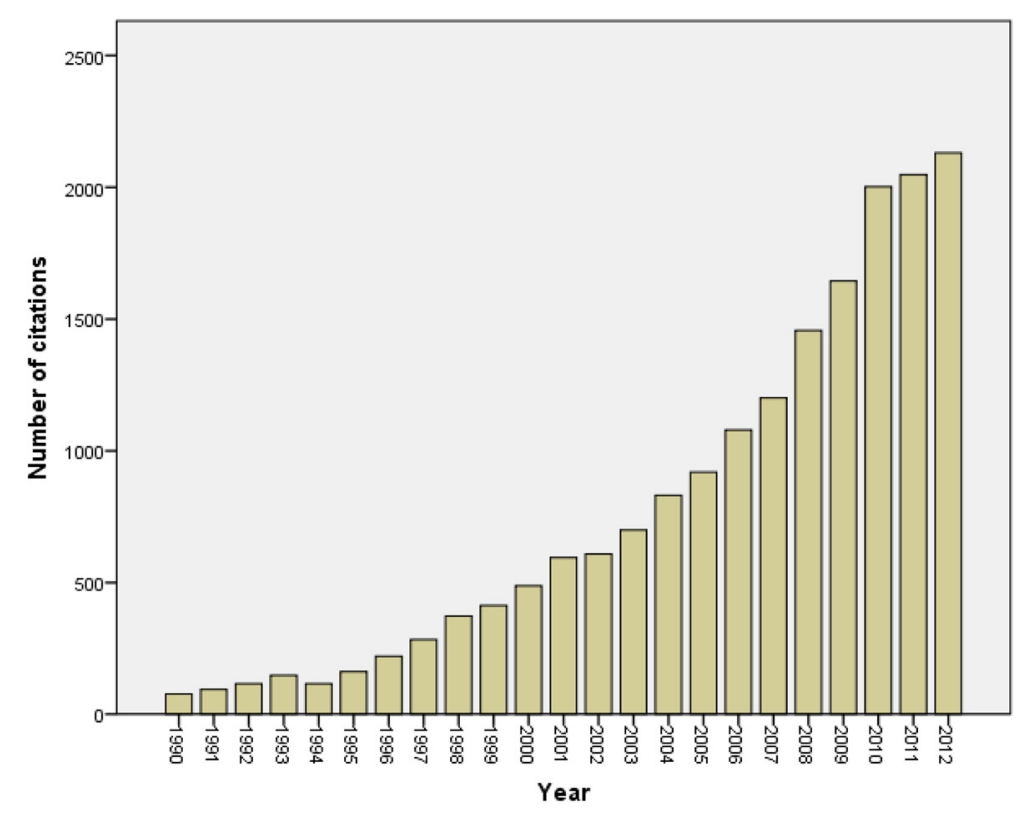

Figure 2 Changes in total number of citation in the past 2 decades for ophthalmology documents published from Arab countries

ophthalmology have to travel abroad to get a specialization degree in ophthalmology. This affected the number of practicing clinical ophthalmologist in Arab countries and hence the research activity in this field. The second potential reason is the lack of governmental and nongovernmental financial support for research in the field of ophthalmology and its public health and economic impact on Arab nations. No doubt that Arabs are lagging behind in most medical fields (Benamer and Bakoush 2009), yet, the consequences of ophthalmic problems such as blindness is an emotionally and economically devastating problem.

In the present study, 2083 documents were analyzed based on ISI web of science database. First of all, it should be stated that this number does not represent $100 \%$ of the ophthalmology research output from Arab countries. It should be noted that some journals are not indexed in ISI web of science and therefore publications from the Arab countries in non-indexed journals were not counted. For example, articles pertaining to ophthalmology that were published in Saudi Journal of Ophthalmology or Journal of the Egyptian Ophthalmological Society were not included in the analysis since these journals are not indexed in ISI Web of Science. Nevertheless, the results obtained represent the genuine research from Arab countries published in international journals with high reputation. This is actually a closer and more accurate presentation of the status of ophthalmology research in Arab countries. Furthermore, the data obtained in our study will serve as a baseline data for future evaluation and for comparative purposes with other medical fields or with ophthalmology research in non-Arab countries.
It was expected that ophthalmology research output was highest from KSA and Egypt. It is believed that these 2 countries had the highest research productivity in other medical fields (Shaban and Abu-Zidan 2003; Tadmouri and Bissar-Tadmouri 2003; Waast and Rossi 2010). This is explainable by the fact that KSA is a rich country and a lot of financial support has been pumped into medical research and services in KSA. In case of Egypt, being the largest in population size in Arab countries, contributes to the high research productivity compared with other Arab countries. Actually, the history of medicine and ophthalmology in Egypt goes back thousands of years ago (Maccallan 1925a, b, 1927; Bey 1929; Dollfus 1956; Bieganowski 2003; Eltoukhi 2003; Coster 2009). Furthermore, international collaboration in the field of ophthalmology research seems high in KSA and Egypt. International collaboration is an important method and mechanism to improve the quantity and quality of research productivity (Lee and Bozeman 2005; Abramo et al. 2009). Furthermore, the international collaboration can draw attention and increase the visibility of scientific publication from Arab countries (Basu and Kumar 2000). No doubt that collaboration with countries like USA, England and other European countries helps in capacity building in the field of ophthalmology.

Research output studies in the field of ophthalmology have been conducted in several parts of the world. Screening the literature shows at least 10 different bibliometric studies in the field of ophthalmology and ophthalmology-related topics (Davis and Wilson 2003; Ohba 2005; Guerin et al. 2009; Kumaragurupari et al. 2010; Waast and Rossi 2010; Liu et al. 2011; Wu et al. 
2011; Xu et al. 2011; Zhao et al. 2011; Jiao et al. 2012; Dai et al. 2013; Huang et al. 2013; Liu et al. 2013). Of particular interest is an article published about worldwide geographical distribution of ophthalmology publications (Guerin et al. 2009). The authors concluded that the greatest gross contributors to ophthalmology publications were USA, England and Japan. However, population adjusted analysis showed that Singapore, Iceland, and Australia were the most prolific nations (Guerin et al. 2009). In the same article, Israel came as one of the top 10 prolific nations which support the findings of our study that showed high quantity and quality of ophthalmology research from Israel compared to Arabs, Turkey and Iran. Another interesting published document is one about contribution of Iran to ophthalmology publications (Katibeh et al. 2011). The authors of the study concluded that although contribution of Iranian scientists to the field is growing, the Iranian nation needs to do more to bridge the gap with other nations and to be more presented in the field worldwide (Katibeh et al. 2011).

Finally, our study has points of strengths and certain points of limitations. Our study is the first article to analyze the quantity and quality of research productivity in the field of ophthalmology from Arab region. Although the study showed that contribution of Arab nations to the field is low, the main purpose of this study is well delivered which is to direct attention and initiate discussion among ophthalmologists in this regard. Our study is not without limitations, most of which have been mentioned in other similar studies (Sweileh et al. 2014b; Sweileh et al. 2014c; Sweileh et al. 2014e, f). The use of ISI web of knowledge database made our study confined to documents published in journals indexed in ISI web of science. Furthermore, many articles in ophthalmology published from Arab countries might have been published in non-ophthalmology journals.

\section{Conclusion}

The present data show promising increase but relatively low ophthalmology research productivity from Arab countries. Wide variation in research productivity among Arab countries do exists with KSA and Egypt being in the top while many other Arab countries had very low productivity. Compared with other non-Arab countries in the Middle East, Arab countries showed lesser quantity of ophthalmology publications than Israel and Turkey but higher than that in Iran. Arab countries, particularly those in the field of ophthalmology need to establish links and research collaboration with other well developed countries in the field.

\section{Abbreviations}

SPSS: Statistical Package for Social Sciences; ISI: Institute for Scientific Information; KSA: Kingdom of Saudi Arabia; UAE: United Arab Emirates;
SAR: Syrian Arab Republic; USA: United States of America; JCR: Journal Citation Report; IRB: Institutional Review Board; SCR: Standard Competition Ranking; IFs: Impact factors; SJR: Scientific Journal Ranking.

\section{Competing interests}

The authors declare that they have no competing interests.

\section{Authors' contributions}

All authors were involved in drafting the article and all authors approved the final version to be submitted for publication. All authors have added an intellectual significant value to the manuscript. WS and SZ were involved in study design and concept. SA, YS, and AS were involved in data analysis and manuscript writing.

\section{Acknowledgements}

The authors would like to express many thanks and gratitude to An-Najah University for help in conducting this study.

\section{Author details}

${ }^{1}$ Department of Pharmacology and Toxicology, College of Medicine and Health Sciences, An-Najah National University, Nablus, Palestine. ${ }^{2}$ Department of Clinical and Community Pharmacy, College of Medicine and Health Sciences, An-Najah National University, Nablus, Palestine. ${ }^{3}$ Department of Opthalmology, College of Medicine and Health Sciences, An-Najah University Hospital, Nablus, Palestine.

Received: 8 November 2014 Accepted: 8 January 2015

Published online: 01 February 2015

\section{References}

Abramo G, D'Angelo CA, Di Costa F (2009) Research collaboration and productivity: is there correlation? High Educ 57(2):155-171

Al-Khader AA (2004) Enhancing research productivity in the Arab world. Saudi Med J 25(10):1323-1327

Baldock C, Ma R, Orton CG (2009) The $h$ index is the best measure of a scientist's research productivity. Med Phys 36:1043

Basu A, Kumar BSV (2000) International collaboration in Indian scientific papers. Scientometrics 48(3):381-402

Benamer HT, Bakoush O (2009) Arab nations lagging behind other Middle Eastern countries in biomedical research: a comparative study. BMC Med Res Methodol 9(1):26

Bey NF (1929) Ophthalmology in Egypt. Br J Ophthalmol 13(11):587

Bieganowski L (2003) Notes on the state of ophthalmology in the ancient Egypt. Klin Oczna 105(1-2):110-113

Bissar-Tadmouri N, Tadmouri GO (2009) Bibliometric analyses of biomedical research outputs in Lebanon and the United Arab Emirates (1988-2007). Saudi Med J 30(1):130-139

Coster DJ (2009) Ancient Egypt to modern ophthalmology: via Otago, New Zealand. Clin Experiment Ophthalmol 37(8):810-813

Dai YL, Sun K, Wang W, Zhang YX, Wei SH, Huang HB (2013) Bibliometric analysis of research articles on traumatic optic neuropathy. Int Eye Sci 13(2):400-404

Davis M, Wilson CS (2001) Elite researchers in ophthalmology: Aspects of publishing strategies, collaboration and multi-disciplinarity. Scientometrics 52 (3):395-410

Davis M, Wilson CS (2003) Research contributions in ophthalmology: Australia's productivity. Clin Experiment Ophthalmol 31(4):286-293

Dollfus MA (1956) Ophthalmology in ancient Egypt. Bull Soc Ophtalmol Fr 10:880-893

Eltoukhi EM (2003) The development of pediatric ophthalmology and strabismus in Egypt. J AAPOS 7(5):309-310

Fan JC, MCGhee CN (2008) Citation analysis of the most influential authors and ophthalmology journals in the field of cataract and corneal refractive surgery 2000-2004. Clin Experiment Ophthalmol 36(1):54-61

Farhat T, Abdul-Sater Z, Obeid M, Arabi M, Diab K, Masri S, Al Haless Z, Nemer G, Bitar F (2013) Research in congenital heart disease: a comparative bibliometric analysis between developing and developed countries. Pediatr Cardiol 34 (2):375-382

Gorini R (2003) Al-Haytham the Man of Experience. First Steps in the Science of Vision. JISHIM 2(4):53-55

Guerin MB, Flynn TH, Brady J, O'Brien CJ (2009) Worldwide geographical distribution of ophthalmology publications. Int Ophthalmol 29(6):511-516 
Huang WB, Wang W, Zhou MW, Chen SD, Zhang XL (2013) Bibliometric analysis of current glaucoma research based on Pubmed database. Zhonghua Yan Ke Za Zhi 49(11):987-992

Huff TE (2003) The rise of early modern science: Islam. Cambridge University Press, China and the West

Inhorn Millar M, Lane SD (1988) Ethno-ophthalmology in the Egyptian delta: an historical systems approach to ethnomedicine in the middle east. Soc Sci Med 26(6):651-657

Jiao JH, Su Z, Wang YH, Hou L, Shang Y, Fu J, Liu L (2012) Bibliometric analysis of anesthesia for cataract surgery based on Web of Science ISI database. Int Eye Sci 12(10):2025-2028

Katibeh M, Moein H-R, Javadi M-A (2011) Contribution of Iran to the Ophthalmic Literature over the Past Three Decades. J Ophthalmic Vis Res 6(3):225-226

Kotb AA, Hammouda EF, Tabbara KF (2006) Childhood blindness at a school for the blind in Riyadh, Saudi Arabia. Ophthalmic Epidemiol 13(1):1-5

Kumaragurupari R, Sieving PC, Lalitha P (2010) A bibliometric study of publications by Indian ophthalmologists and vision researchers, 2001-06. Indian J Ophthalmol 58(4):275-279

Lee S, Bozeman B (2005) The impact of research collaboration on scientific productivity. Soc Stud Sci 35(5):673-702

Liu L, Jiao JH, Chen L (2011) Bibliometric study of diabetic retinopathy during 2000-2010 by ISI. Int J Ophthalmol 4(4):333-336

Liu L, Wu JY, Liu LM, Chen L (2013) Bibliometric study of literatures on ophthalmic epidemiology and prevention of blindness during 2001-2010. Int Eye Sci 13(9):1869-1871

Maccallan AF (1925a) Ophthalmology in Egypt. Br Med J 1(3351):551-552

Maccallan AF (1925b) Tropical Ophthalmology (Egypt). Proc R Soc Med 18:41-44

Maccallan AF (1927) The History of Ophthalmology in Egypt. Br J Ophthalmol 11 (12):602-609

Majeed A (2005) How Islam changed medicine. BMJ 331(7531):1486-1487

Mansour A, Kassak K, Chaya M, Hourani T, Sibai A, Alameddine M (1997) National survey of blindness and low vision in Lebanon. Br J Ophthalmol 81(10):905-906

Ohba N (2005) Bibliometric analysis of the current international ophthalmic publications. Nippon Ganka Gakkai Zasshi 109(3):115-125

Olitsky PK, Tyler JR (1933) Trachoma in Egypt. Arch Ophthalmol 10(4):440

Prioreschi P (2006) Anatomy in Medieval Islam. J Int Soc History Islamic Med 5:2-6

Ragghianti CP, Martínez R, Martins J, Gallo JE (2006) Comparative study of scientific publications in Ophthalmology and visual Sciences in Argentina, Brazil, Chile, Paraguay and Uruguay (1995-2004). Arq Bras Oftalmol 69(5):719-723

Saadi H, Carruthers SG, Nagelkerke N, Al-Maskari F, Afandi B, Reed R, Lukic M, Nicholls MG, Kazam E, Algawi K (2007) Prevalence of diabetes mellitus and its complications in a population-based sample in Al Ain, United Arab Emirates. Diabetes Res Clin Pract 78(3):369-377

Schreiber M (2013) How relevant is the predictive power of the h-index? A case study of the time-dependent Hirsch index. J Informetrics 7(2):325-329

Shaban SF, Abu-Zidan FM (2003) A quantitative analysis of medical publications from Arab countries. Saudi Med J 24(3):294-296

Sweileh WM, Zyoud SH, Al-Jabi SW, Sawalha AF (2014a) Bibliometric analysis of diabetes mellitus research output from Middle Eastern Arab countries during the period (1996-2012). Scientometrics 101(1):819-832

Sweileh WM, Al-Jabi SW, Zyoud SH, Sawalha AF (2014b) Bronchial asthma and chronic obstructive pulmonary disease: research activity in Arab countries. Multidiscip Respir Med 9(1):38

Sweileh WM, Al-Jabi SW, Zyoud SH, Sawalha AF, Ghanim MA (2014c) Osteoporosis is a neglected health priority in Arab World: a comparative bibliometric analysis. Springerplus 3:427

Sweileh WM, Zyoud SH, Al-Jabi SW, Sawalha AF (2014d) Assessing urology and nephrology research activity in Arab countries using ISI web of science bibliometric database. BMC Res Notes 7:258

Sweileh WM, Zyoud SH, Al-Jabi SW, Sawalha AF (2014e) Quantity and quality of obesity-related research in Arab countries: assessment and comparative analysis. Health Res Policy Syst 12:33

Sweileh WM, Zyoud SH, Al-Jabi SW, Sawalha AF (2014f) Substance use disorders in Arab countries: research activity and bibliometric analysis. Subst Abuse Treat Prev Policy 9:33

Syed IB (2002) Islamic Medicine: 1000 years ahead of its times. J Int Soc History Islamic Med 2:2-9

Tabbara KF (2001) Blindness in the eastern Mediterranean countries. Br J Ophthalmol 85(7):771-775

Tabbara KF, Blodi FC (1987) Ophthalmology in Saudi Arabia. Arch Ophthalmol 105(6):861-864
Tadmouri GO, Bissar-Tadmouri N (2003) Biomedical publications in an unstable region: the Arab world, 1988-2002. Lancet 362(9397):1766

Waast R, Rossi P-L (2010) Scientific Production in Arab Countries A Bibliometric Perspective. Science Technology \& Society 15(2):339-370

Wagoner MD, al-Rajhi AA (2001) Ophthalmology in the Kingdom of Saudi Arabia. Arch Ophthalmol 119(10):1539-1543

Wallin JA (2005) Bibliometric methods: pitfalls and possibilities. Basic Clin Pharmacol Toxicol 97(5):261-275

Whiting DR, Guariguata L, Weil C, Shaw J (2011) IDF diabetes atlas: global estimates of the prevalence of diabetes for 2011 and 2030. Diabetes Res Clin Pract 94(3):311-321

Wu JB, Xu CT, Wang BL (2011) Bibliometric analysis of the literature of cataract in PubMed database during 1813-2010. Int J Ophthalmol 11(9):1577-1581

Xu CT, Li SQ, Lü YG, Pan BR (2011) Development of biomedical publications on ametropia research in PubMed from 1845 to 2010: A bibliometric analysis. Int J Ophthalmol 4(1):1-7

Zhao ZG, Guo XG, Xu CT, Pan BR, Xu LX (2011) Bibliometric analysis on retinoblastoma literatures in PubMed during 1929 to 2010. Int J Ophthalmol 4(2):115-120

Zyoud SH, Al-Jabi SW, Sweileh WM (2014a) Bibliometric analysis of scientific publications on waterpipe (narghile, shisha, hookah) tobacco smoking during the period 2003-2012. Tob Induc Dis 12(1):7

Zyoud SH, Al-Jabi SW, Sweileh WM (2014b) Worldwide research productivity of paracetamol (acetaminophen) poisoning: a bibliometric analysis (2003-2012) Hum Exp Toxicol 34(1):12-23

Zyoud SH, Al-Jabi SW, Sweileh WM, Awang R (2014c) A bibliometric analysis of research productivity of Malaysian publications in leading toxicology journals during a 10-year period (2003-2012). Hum Exp Toxicol 33(12):1284-1293

Zyoud SH, Al-Jabi SW, Sweileh WM, Awang R (2014d) A bibliometric analysis of toxicology research productivity in Middle Eastern Arab countries during a 10-year period (2003-2012). Int J Ophthalmol 12(1):4

Zyoud SH, Al-Jabi SW, Sweileh WM, Awang R (2014e) A Scopus-based examination of tobacco use publications in Middle Eastern Arab countries during the period 2003-2012. Harm Reduct J 11:14

\section{Submit your manuscript to a SpringerOpen ${ }^{\odot}$ journal and benefit from:}

- Convenient online submission

$\checkmark$ Rigorous peer review

- Immediate publication on acceptance

- Open access: articles freely available online

- High visibility within the field

- Retaining the copyright to your article

Submit your next manuscript at $>$ springeropen.com 